\title{
Pulmonary hypertension accompanying ventricular septal defect and patent ductus arteriosus. Management in infancy and early childhood
}

\author{
JOHN M REID, ERIC N COLEMAN, AND JOHN G STEVENSON \\ From the University of Cardiology, Royal Hospital for Sick Children, Glasgow, \\ and the Cardiothoracic Unit, Mearnskirk Hospital, Glasgow, UK
}

ABSTRACT Forty-one infants and children with the combination of patent ductus arteriosus (PDA) and ventricular septal defect (VSD) were encountered over 20 years. Twenty-four presented in infancy with congestive cardiac failure. Pulmonary hypertension was present in 32 , the cause in 19 being increased pulmonary blood flow. Increased pulmonary vascular resistance (PVR) was detected in 13 (indicated by a pulmonary to systemic resistance ratio (Rp : RS) $>0.24: 1$ and PVR $>4$ units). Thus $22 \%$ had a pulmonary artery systolic pressure less than $30 \mathrm{mmHg}$ and $68 \%$ had a pulmonary vascular resistance below four units, indicating an unusually mild form of the combined condition in these patients. Surgical management is discussed, and in particular the question of simultaneous closure of the defects during infancy. Cardiac failure, resistant to drug treatment, and increased PVR are indications of operation. The PDA should be closed and only if there is no substantial fall in pulmonary artery pressure is the VSD repaired.

Although both ventricular septal defect (VSD) and patent ductus arteriosus (PDA) are common congenital cardiac anomalies occurring singly, the two combined are relatively uncommon (Hallman et al, 1964; Cartmill et al, 1966; Keith et al, 1978).

Because of the existence of two separate systemic-pulmonary arterial shunts, pulmonary hypertension would be expected as a common accompaniment and congestive cardiac failure a common presentation in infancy. We present our experience with this combination of defects in 41 infants and children, most of whom were under the age of 2 years.

\section{Patients and methods}

During 1959-78 41 infants and children presented with the combination of PDA and VSD. Patients with additional anomalies (atrial septal defect, coarctation of aorta, and aortic stenosis) were excluded. Thirty-two patients were female and nine male, the age at presentation ranging from 1 month to 11 years (mean 19.7 months) (table 1 ). Twenty-four presented with congestive cardiac failure in the first 12 months of life. After the institution of medical treatment, cardiac catheter-
Table 1 Age range of 41 patients $(24<1$ year $)$

\begin{tabular}{llll}
\hline Age & & \\
\hline $0-3 / 12$ & $3 / 12-1$ year & $1-2$ years & $>2$ years \\
18 & 6 & 7 & 10 \\
\hline
\end{tabular}

isation and angiocardiography were performed in these infants, as it was in the older children all of whom were symptom-free, as a prelude to possible surgical treatment. In 39 patients the patent ductus was catheterised. The following information was obtained: pulmonary artery systolic pressure, pulmonary to systemic systolic pressure ratio $N$ (Pp: Ps), pulmonary: systemic blood flow ratio N (Qp : Qs), pulmonary vascular resistance (PVR), $\sigma$ and pulmonary to systemic resistance ratio (Rp: Rs). The data obtained did not allow the calculation with accuracy of the volume of shunt of the PDA or VSD individually.

\section{Results}

HAEMODYNAMIC DATA

Clinical and haemodynamic data are shown in table 2. Pulmonary hypertension was recorded in 
Table 2 Haemodynamic data in 41 patients

\begin{tabular}{|c|c|c|c|c|c|c|c|c|c|}
\hline \multicolumn{2}{|c|}{$P A$ pressure systolic $(\mathrm{mmHg})$} & \multicolumn{2}{|l|}{$P p: P s$} & \multicolumn{2}{|c|}{$Q p: Q s$} & \multicolumn{2}{|c|}{$P V R$ (units) } & \multicolumn{2}{|l|}{$R p: R s$} \\
\hline$<30$ & $30-110$ & $<0.8$ & $>0.8$ & $<1.5$ & $>1 \cdot 5$ & $<4$ & $>4$ & $<0.24$ & $>0.24$ \\
\hline 9 & 32 & 27 & 14 & 10 & 31 & 25 & 16 & 28 & 13 \\
\hline
\end{tabular}

32 cases, the upper limit of normal systolic pressure being accepted as $30 \mathrm{mmHg}$. The pulmonary artery systolic pressure range for the entire series was 20 to $110 \mathrm{mmHg}$ (mean 46). The Pp : Ps ratio range was $0.22: 1$ to $1.3: 1$ (mean $0.69: 1$ ). The Qp : Qs ratio range was $1: 1$ to $7: 1$ (mean $1.9: 1$ ). The pulmonary vascular resistance range was 1 to 12 units (mean 4). The $\mathrm{Rp}: \mathrm{Rs}$ ratio range was $0.08: 1$ to $0.60: 1$ (mean $0 \cdot 19: 1$ ) and exceeded $0 \cdot 40: 1$ in only three patients.

\section{SURGICAL PROCEDURES}

Repair of the PDA alone was performed in 19 patients. In the earliest part of the series banding of the main pulmonary artery was carried out in nine patients when no drop in pulmonary artery pressure occurred after PDA closure. PDA closure along with repair of the VSD was performed in nine of the later cases (table 3). Two of the nine infants who had main pulmonary artery banding died immediately after operation. Of the seven survivors, four subsequently underwent surgical repair of the VSD and main pulmonary artery reconstruction, and one awaits this procedure; in one the VSD closed spontaneously and pulmonary artery reconstruction only was required; in the seventh the VSD was shown by cardiac catheterisation and angiocardiography to have closed spontaneously, and unaccountably no gradient could be shown across the banded pulmonary artery. Four patients had no surgical treatment; one died shortly after catheterisation, possibly as a result of recurrence of serious dysrhythmia; one was grossly mentally handicapped; one who had cardiac failure in early infancy but without catheterisation evidence of pulmonary vascular disease is well and thriving at the age of 10 months; and in the fourth both defects had apparently undergone spontaneous closure by the age of 4 years.

Table 3 Surgical procedures (deaths in parentheses)

\begin{tabular}{lclll}
\hline & $\begin{array}{l}\text { Closure } \\
P D A \text { alone }\end{array}$ & $\begin{array}{l}\text { PDA+ } \\
\text { banding } \\
M P A\end{array}$ & $\begin{array}{l}\text { PDA } \\
\text { VSD } \\
\text { repair }\end{array}$ & No surgery \\
\hline Total number & $19(0)$ & $9(2)$ & $9(3)$ & $4(1)$ \\
No under 1 year & 6 & $9(2)$ & $5(1)$ & $4(1)$ \\
\hline
\end{tabular}

PULMONARY HYPERTENSION AND PULMONARY VASCULAR DISEASE

The terms pulmonary hypertension and pulmonary vascular disease are not synonymous, as pulmonary hypertension may be present without any accompanying changes in the pulmonary vasculature. In the context of congenital heart disease pulmonary hypertension is due either to increased pulmonary blood flow or to increased resistance in the lungs that may result from structural changes in the pulmonary arterial tree. Because of difficulty we had experienced with the interpretation of lung biopsy histology the assessment of pulmonary vascular disease was based solely on the haemodynamic findings.

Thirty-two patients (78\%) had pulmonary hypertension, 12 of whom had PDA closure alone, nine PDA ligation with pulmonary artery banding, eight repair of both PDA and VSD, and three no surgical treatment. In 19 of these 32 the pulmonary hypertension was due simply to increased flow, as the Qp : Qs ratio was high, and neither the PVR nor the $\mathrm{Rp}: \mathrm{Rs}$ ratio was raised. In 13 patients $(32 \%$ of the 41$)$ the PVR was increased, the PVR measuring four units or more, and the Rp: Rs ratio exceeding 0.24:1 (tables 4 and 5). Three had PDA closure, three PDA closure with pulmonary artery banding, three PDA closure with VSD repair, and four had no surgical treatment. Two of the six deaths occurred in those with increased PVR. Cardiac catheterisation in three patients after surgical treatment showed a fall in pulmonary vascular resistance (figure).

\section{DEATHS}

There were six deaths, one after catheterisation and five immediately after operation. A high PVR was present in two of these and contributed to a fatal outcome (table 4).

SPONTANEOUS REDUCTION OR CLOSURE OF VSD In nine patients there was documented evidence, either from clinical and radiographic assessment or by repeat catheterisation, of spontaneous closure of the VSD during the period of follow-up. This occurred in six patients who underwent PDA closure alone, in two who had PDA closure with pulmonary artery banding, and in one who had no 
Table 4 Thirteen patients with pulmonary vascular disease $(R p: R s>0.24)$

\begin{tabular}{|c|c|c|c|c|c|c|c|c|}
\hline Patient & Age & $\begin{array}{l}P A \\
\text { pressure } \\
\text { systolic } \\
(\mathrm{mmHg})\end{array}$ & $P p: P s$ & $Q p: Q s$ & $\begin{array}{l}P V R \\
\text { (units) }\end{array}$ & $R p: R s$ & Procedure & Outcome \\
\hline \multirow[t]{2}{*}{3} & $5 / 12$ & 79 & $1 \cdot 30$ & $3 \cdot 80$ & 4 & 0.25 & - & - \\
\hline & 4 yr & 100 & $1 \cdot 00$ & $2 \cdot 00$ & 8 & 0.80 & PDA + VSD repaired & Well \\
\hline \multirow[t]{2}{*}{4} & $3 / 12$ & 100 & 0.61 & $1 \cdot 10$ & 12 & 0.61 & Banding + PDA & Well \\
\hline & $5 \mathrm{yr}$ & 60 & 0.40 & $2 \cdot 40$ & 6 & 0.30 & VSD repaired & Well \\
\hline 5 & $1 / 12$ & 56 & $0 \cdot 70$ & $2 \cdot 50$ & 7 & $0 \cdot 25$ & - & MD deteriorating \\
\hline 7 & $11 \mathrm{yr}$ & 110 & $1 \cdot 00$ & 1.00 & 11 & 0.60 & - & Deteriorating \\
\hline 9 & $2 / 12$ & 50 & 1.00 & $1 \cdot 25$ & 4 & 0.38 & - & Awaiting repeat $C C$ \\
\hline \multirow[t]{2}{*}{12} & $1 / 12$ & 80 & $1 \cdot 00$ & 3 & 6 & 0.25 & Banding + PDA & Well \\
\hline & 5 yr & 30 & $0 \cdot 30$ & 1 & 1 & $0 \cdot 10$ & - & Repeat CC-VSD closed \\
\hline 16 & $1 / 12$ & 49 & 0.54 & $1 \cdot 60$ & 6 & 0.30 & - & VSD and PDA closed spontaneously \\
\hline \multirow[t]{2}{*}{20} & $1 / 12$ & 90 & $1 \cdot 00$ & $1 \cdot 90$ & 7 & 0.38 & PDA ligated & Well \\
\hline & $8 \mathrm{yr}$ & 38 & $0 \cdot 30$ & $1 \cdot 20$ & 2 & $0 \cdot 10$ & - & VSD closed spontaneously \\
\hline 21 & 3 yr & 65 & 0.72 & 2 & 8 & $0 \cdot 28$ & PDA ligated & VSD closed spontaneously \\
\hline 26 & $1 \mathrm{yr}$ & 79 & $1 \cdot 00$ & $3 \cdot 30$ & 7 & 0.25 & PDA + VSD repaired & Died after operation \\
\hline 30 & $2 / 12$ & 60 & 0.70 & $1 \cdot 50$ & 4 & 0.50 & Banding + PDA & Died \\
\hline 36 & 1 yr & 55 & 0.61 & $1 \cdot 20$ & 6 & 0.30 & PDA ligated & VSD closed spontaneously \\
\hline 41 & $3 / 12$ & 50 & 0.90 & $2 \cdot 40$ & 5 & 0.83 & PDA + VSD repaired & Well \\
\hline
\end{tabular}

VSD $=$ Ventricular septal defect.

PDA $=$ Patent ductus arteriosus.

MD $=$ Mentally defective.

$\mathrm{CC}=$ Cardiac catheterisation

Table 5 Comparison of haemodynamic data in patients without and those with pulmonary vascular disease (mean values only)

\begin{tabular}{llllll}
\hline & $P A$ & $P p: P s$ & $Q p: Q s$ & $P V R$ & $R p: R s$ \\
\hline $\begin{array}{l}\text { No pulmonary } \\
\text { vascular disease (28) }\end{array}$ & 47.5 & 0.61 & 3.5 & 2.7 & 0.13 \\
$\begin{array}{c}\text { Pulmonary vascular } \\
\text { disease (13) }\end{array}$ & 71 & 0.86 & 2 & 7 & 0.40 \\
\hline
\end{tabular}
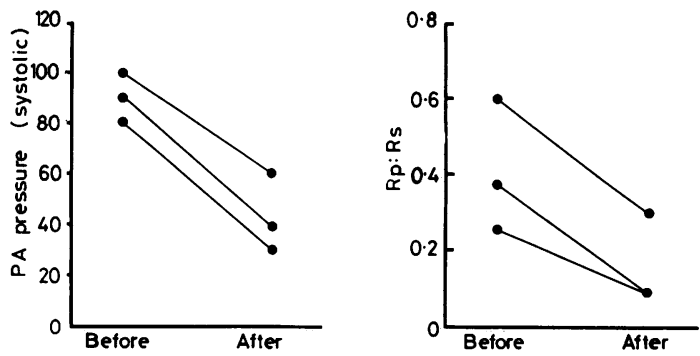

Comparison of PA pressure (systolic) and $R p: R s$ at preliminary and repeat catheter studies in three patients.

surgical treatment. There was evidence of reduction in the size of the VSD in the remaining 13 patients who had PDA closure alone (table 6).

\section{Discussion}

Although relatively uncommon, the combination of PDA with VSD should be recognised. Hallman
Table 6 Spontaneous closure or reduction in size of VSD during follow-up

\begin{tabular}{lllll}
\hline & $\begin{array}{l}\text { PDA closure PDA closure PDA closure } \\
\text { alone } \\
(19)\end{array}$ & $\begin{array}{l}\text { No surgery } \\
\text { and PA } \\
\text { banding } \\
(9)\end{array}$ & $\begin{array}{l}\text { and VSD } \\
\text { repair } \\
(9)\end{array}$ & $(4)$ \\
\hline $\begin{array}{l}\text { Spontaneous } \\
\text { closure of } \\
\text { VSD (9) }\end{array}$ & 6 & 2 & 0 & 1 \\
$\begin{array}{l}\text { Reduction in } \\
\text { size of } \\
\text { VSD (13) }\end{array}$ & 13 & 0 & 0 & 0 \\
\hline
\end{tabular}

et al (1964) found a PDA in $13(2.6 \%)$ of 500 surgically treated patients with VSD and Cartmill et al (1966) recorded $25(6 \%)$ in 447 patients so treated. On the other hand, Keith et al (1978) recorded from the Toronto Cardiac Registry a VSD in $5 \%$ of patients with a PDA.

Pulmonary vascular disease in association with VSD has been well documented (Hallman et al, 1964; Lillehei et al, 1964; Cartmill et al, 1966; Hallidie-Smith et al, 1969). Although the condition can only be diagnosed with certainty on histological grounds (Heath and Edwards, 1958), useful parameters based on haemodynamic data can be used to predict the presence or absence of pulmonary vascular disease. Kirklin (1965) stated that the most reliable guide was the ratio of the pulmonary to the systemic resistance (Rp:Rs); a figure above $0 \cdot 25: 1$ was indicative of increased PVR. Hallidie-Smith et al (1969) regarded a PVR above eight units as their yardstick, but the 42 children in their study were all in an older age 
group (range 3 to 12 years). More recently Yasui et al (1977) found that simply relating the peak systolic pulmonary artery pressure to the peak systolic systemic pressure (Pp: Ps) was of great practical value in determining the need for surgical treatment in a group of 87 children under the age of 5 years. A ratio of $0 \cdot 8: 1$ was an indication for early operation to prevent the development of pulmonary vascular disease, but below this figure infants could safely be left until their first birthday. If at reinvestigation the haemodynamic picture had not improved, operation was then carried out.

For many years the recommended procedure for infants with intractable cardiac failure associated with a large VSD with pulmonary hypertension was pulmonary artery banding, followed in later childhood by repair of the defect and pulmonary artery reconstruction (Muller and Damman, 1952; Hallman et al, 1966; Reid et al, 1968; Stark et al, 1969; Coleman et al, 1972). This procedure has now been superseded in large measure by primary repair of the defect in infancy when indicated (Cartmill et al, 1966; Yasui et al, 1977; Fox et al, 1978).

The management of infants and young children with pulmonary hypertension accompanying the combined lesions of VSD and PDA is not so clear. Whether both lesions require immediate surgical treatment in infancy, or whether operation can be safely deferred till later childhood when the VSD may have undergone spontaneous closure or natural reduction in size and the PDA may have closed is still controversial. In nine of our patients spontaneous closure of the VSD was observed, and in a further 13 natural reduction in size occurred. Goor and Lillehei (1975), while recognising that both lesions are best corrected at a single operation, recommended that in a sick infant with congestive heart failure PDA closure alone was preferable, particularly when the shunt through the PDA was large and that through the VSD was small.

We have attempted to arrive at a satisfactory management policy by analysing our experience in 41 children during a 19-year period. Our policy was to catheterise all who had developed congestive cardiac failure, and to proceed with operation either when there was evidence of serious pulmonary hypertension or when there was failure to thrive. Closure of the PDA was performed and if the pulmonary artery pressure dropped significantly nothing else was done. If the pressure remained high pulmonary artery banding was then performed to be superseded in recent years by repair of the defect as the method of choice. Clearly surgical treatment is not necessary in all patients with VSD and PDA and accompanying pulmonary hypertension during the first year of life. Although in our experience closure of the PDA alone carried no mortality, repair of the VSD certainly did. Cartmill et al (1966) had a mortality of $5 \%$ when surgical repair of a VSD was carried out in infancy. More recently Fox et al (1978) have recorded a fall in mortality to $1.9 \%$, but they did not equate the risk of operation with the presence or absence of pulmonary vascular disease. The almost imponderable balance of risks is between that of operation and that of the development of pulmonary vascular obstruction. Clearly operation should not be deferred too long if PVR is raised and appears to be progressing at repeated catheter studies. Pulmonary vascular disease may be capable of regressing completely up to the age of 2 years if the causal defect or defects are repaired (Lillehei et al, 1964), but if operation is left until after childhood this is less likely to take place (Lynfield et al, 1961; Hallidie-Smith et al, 1969, 1977). One of our patients (case 3) was found to have pulmonary hypertension with a PVR of four units and Rp: Rs ratio of $0 \cdot 25: 1$ at the age of 5 months. Operation was deferred as the infant was thriving and the pulmonary blood flow was high (Qp : Qs 3.8:1). She did not return for critical review until the age of 4 years when catheter studies indicated that pulmonary vascular obstruction had developed. Although the PDA and VSD were then repaired, the pulmonary artery pressure did not fall immediately, and the outlook is viewed with concern.

We would conclude that congestive cardiac failure in infancy is an indication for early investigation. If cardiac catheterisation confirms the presence of a large left to right shunt accompanied by pulmonary hypertension, early operation is necessary. The PDA should be closed, and only if there is no substantial fall in pulmonary artery pressure is the VSD repaired. Investigation should be repeated at or around the first birthday in those in whom the VSD was not repaired and in any others in whom operation was deferred. The presence of persistent pulmonary hypertension or early pulmonary vascular disease (indicated by an Rp : Rs $>0.25: 1$ or PVR $>4$ units) makes early repair of the residual defect or defects obligatory to prevent the development of permanent structural changes in the pulmonary vasculature. Clearly the management of this double defect must be kept under review, the critical features in the argument being the mortality of VSD repair in 
larger series than have been published to date, particularly in relation to infants with increased pulmonary vascular resistance, and improved understanding of the risk of irreversible pulmonary vascular disease inherent in the natural history of the condition. Although the concept that one operation should be safer than two is easy to accept, it may still have to be shown conclusively that primary closure of a VSD in infancy is safer than main pulmonary artery banding at that stage, with pulmonary artery reconstruction and repair of any residual ventricular septal defect to follow after a few years.

\section{References}

Cartmill, T B, Du Shane, J W, McGoon, D C, and Kirklin, J W (1966). Results of repair of ventricular septal defect. Journal of Thoracic and Cardiovascular Surgery, 52, 486-501.

Coleman, E N, Reid, J M, Barclay, R S, and Stevenson, J G (1972). Ventricular septal defect repair after pulmonary artery banding. British Heart Journal, 34, 134-138.

Fox, K M, Patel, R G, Graham, G R, Taylor, J F N, Stark, J, De Leval, M R, and Macartney, F J (1978). Multiple and single ventricular septal defect. A clinical and haemodynamic comparison. British Heart Journal, 40, 141-146.

Goor, D A, and Lillehei, C W (1975). Congenital Malformations of the Heart, p 349. Grune and Stratton, New York.

Hallidie-Smith, K A, Hollman, A, Cleland, W P, Bentall, H H, and Goodwin, J F (1969). Effects of surgical closure of ventricular septal defects upon pulmonary vascular disease. British Heart Journal, 31, 246-260.

Hallidie-Smith, K A, Wilson, R S E, Hart, A, and Zeidifard, E (1977). Functional states of patients with large ventricular septal defect and pulmonary vascular disease six to 16 years after surgical closure of their defects in childhood. British Heart Journal, 39, 1093-1101.

Hallman, G L, Cooley, D A, Wolfe, R R, and McNamara, D G (1964). Surgical treatment of ventricular septal defect associated with pulmonary hypertension. Journal of Thoracic and Cardiovascular Surgery, 48, 588-600.
Hallman, G L, Cooley, D A, and Bloodwell, R D (1966). Two-stage surgical treatment of ventricular septal defect. Results of pulmonary artery banding in infants and subsequent open-heart repair. Journal of Thoracic and Cardiovascular Surgery, 52, 476485.

Heath, D, and Edwards, J E (1958). The pathology of $\vec{\circ}$ hypertensive pulmonary vascular disease. A descrip- $\overrightarrow{\vec{\omega}}$ tion of six grades of structural changes in the pul- $\bar{\omega}$ monary arteries with special reference to congenital cardiac septal defects. Circulation, 18, 533-547.

Keith, J D, Rowe, R D, and Vlad, P (1978). Heart Disease in Infancy and Childhood, 3rd edn, p 321. Macmillan, New York.

Kirklin, J (1965). Ventricular septal defect with pul- of monary vascular disease. New Zealand Medical 응 Journal, 64 (Cardiac Supplement), 34-36.

Lillehei, C W, Levy, M J, Adams, P, and Anderson, R C (1964). High-pressure ventricular septal defects. Journal of American Medical Association, 188, 949-952.

Lynfield, J, Gasul, B M, Arcilla, R, and Luan, K L $\vec{\omega}$ (1961). The natural history of ventricular septal 6 defect in infancy and childhood. American Journal of Medicine, 30, 357-371.

Muller, W H, and Damman, J F, jun (1952). The treatment of certain congenital malformations of the heart by the creation of pulmonary stenosis to reduce pulmonary hypertension and excessive pul- $\unrhd$ monary blood flow. Surgery, Gynecology, and $\mathrm{Ob}$ stetrics, 95, 213-219.

Reid, J M, Barclay, R S, Coleman, E N, Stevenson, J G, Welsh, T M, and McSwan, N (1968). Pulmonary artery banding in congenital heart disease associated with pulmonary hypertension. Thorax, 23, 385-391.

Stark, J, Aberdeen, E, Waterston, D J, BonhamCarter, R E, and Tynan, M (1969). Pulmonary artery constriction (banding): 146 cases. Surgery, 65, 808-818.

Yasui, H, Yoshitoshi, M, Miyamoto, A T, Kato, H, Takeda $Y$, Tokunga $K$, Tasaki, $H$, and Tomoika, H (1977). Ventricular septal defect: Selection of 을 patients and timing of surgery. American Heart Journal, 93, 40-50.

Requests for reprints to: Dr John M Reid, Cardiothoracic Unit, Mearnskirk Hospital, Glasgow. 